\section{Perception is everything: how people see ecosystem services can guide management and modeling efforts}

People's perceptions of the world around them can be quite different from reality. Other times, perceptions may be the only source of information if robust scientific data collection has not occured. Knowing what people perceive about their environment can be a useful tool for managers: one could determine where restoration efforts need to be focused, or if more communication and outreach efforts are needed to correct misinformation.

The authors set out to find if perceptions of ecosystem services could help guide decisionmaking for environmental management. Their results indicated, yes. The authors conducted surveys and interviews of coastal residents in Chile's Pudeto estuary to determine perceptions of the state of key ecosystem services (i.e. if wetlands that provide sources of freshwater were in a good, functioning state) and how important residents felt these ecosystem services were to their wellbeing.

In their paper, the authors described ways to determine which ecosystem services matter most to community wellbeing through participatory mapping, key informant interviews, and semi-structured interviews. Once the list of ecosystem services was determined, the authors used a questionnaire to elicit the perceptions of various user-groups. By binning users into groups (like those that directly depended on functional ecosystem services for their livelihoods), the authors could compare and contrast how people perceived the state and importance of different aspects of the estuary. Importantly, the authors included closed and open-ended questions in their survey to determine how people surmised potential management interventions would impact the environment and the wellbeing of them and their families.

The authors note: "Understanding how people perceive the importance of different [ecosystem services] to wellbeing may help to define which [ecosystem services] matter most and to whom. Analysts may then enter [ecosystem services] identified as priorities into models that estimate the provision of those [ecosystem services] under different management scenarios and given biophysical constraints. In this way, analysts could focus on [ecosystem services] perceived as priorities."
This is a summary of: Using people's perceptions of ecosystem services to guide modeling and management efforts

Accessible at: https://marxiv.org/5dua6

Authors:

Tammy L. Elwell, Stefan Gelcich, Steven D. Gaines, David López-Carr

Added to MarXiv: June 2018

Published: Science of the Total Environment, 2018

Suggested Citation: Perception is everything: how people see ecosystem services can guide management and modeling efforts. OCTO (2018). DOI: 10.31230/osf.io/2b6cz

See more MarXiv summaries at https://www.marxivinfo.org/ summaries

Join the MarXiv Summaries monthly newsletter at https:// oct.to/marxivsum

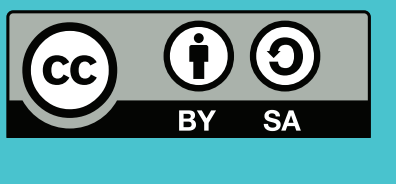

MarXiv is an ОСТO Initiative
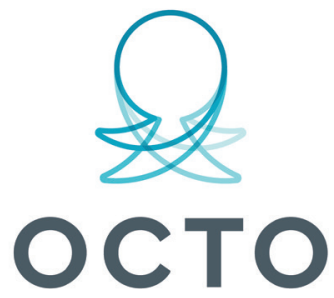

OPEN COMMUNICATIONS FOR THE OCEAN 